\title{
Isolamento e purificação de sideróforos bacterianos: uma abordagem educacional multidisciplinar
}

\author{
Isolation and purification of bacterial siderophores: a multidisciplinary educational approach
}

\begin{abstract}
Washington Luiz Caneschi ${ }^{1 \S}$, Angélica Bianchini Sanchez ${ }^{1 \S^{*}}$, Josielda Gomes Pereira² ${ }^{2}$ Camila Carrião Machado Garcia ${ }^{1,2}$, Leandro Marcio Moreira ${ }^{1,2}$.

${ }^{1}$ Núcleo de Pesquisas em Ciências Biológicas (NUPEB), Universidade Federal de Ouro Preto, Ouro Preto, MG, Brazil. '2Departamento de Ciências Biológicas (DECBI), Instituto de Ciências Exatas e Biológicas, Universidade Federal de Ouro Preto, Campus Morro do Cruzeiro, Ouro Preto, MG, Brazil.
\end{abstract}

$\S$ Estes autores contribuíram igualmente neste trabalho.

*angelisanchez@gmail.com

Support: CAPES, CNPq, FAPEMIG.

\section{Resumo}

As bactérias promovem a captação ambiental de ferro pela produção e secreção de sideróforos, que quelam o ferro e são posteriormente internalizadas para fornecer esse essencial metal ao metabolismo celular. Neste estudo, descrevemos uma sequência didática que permitirá aos estudantes de graduação isolar, purificar parcialmente e classificar os sideróforos produzidos por bactérias de diferentes ambientes. Essa proposta foi avaliada com alunos do mestrado profissional em ensino de ciências abordando parâmetros metodológicos e aprendizagem conceitual associados à metodologia. Os resultados mostraram que essa sequência didática pode trabalhar temáticas bioquímicas em conjunto com uma abordagem multidisciplinar e de baixo custo, permitindo a discussão de questões-chave em diferentes áreas do conhecimento biológico que é frequentemente negligenciada em estudos universitários.

Palavras-chave: aquisição de ferro; cromatografia; aprendizagem integrada e contextualizada.

\begin{abstract}
Bacteria promote environmental iron uptake by the production and secretion of siderophores, which sequester iron and are subsequently internalized to provide this essential metal for cellular metabolism. In this study, we describe a didactic sequence that will enable undergraduate students to isolate, partially purify, and classify siderophores produced by bacteria from different environments. This proposal was evaluated with students of professional master's in science teaching approaching methodological parameters and conceptual learning associated with the methodology. Results shows that this didactic sequence can work biochemical contents in tandem with a multidisciplinary and low-cost approach, allowing for the discussion of key issues in different areas of biological knowledge, which is often neglected in university studies.
\end{abstract}

Keywords: iron acquisition; chromatography; integrated and contextualized learning. 


\section{Ficha da atividade}

\begin{tabular}{|c|c|}
\hline Título & $\begin{array}{l}\text { Isolamento e purificação de sideróforos bacterianos: uma abordagem } \\
\text { educacional multidisciplinar }\end{array}$ \\
\hline Categoria: & Prática de Ensino \\
\hline Tipo & Aulas práticas \\
\hline Público-alvo: & Alunos de graduação em Biologia \\
\hline $\begin{array}{l}\text { Conteúdos } \\
\text { abordados }\end{array}$ & Metabolismo bacteriano, sideróforos, cromatografia \\
\hline $\begin{array}{l}\text { Objetivos } \\
\text { educacionais }\end{array}$ & $\begin{array}{l}\text { Implementar uma sequência didática que permita aos alunos vivenciar a aprendi- } \\
\text { zagem por meio de pesquisas com o tema central, os sideróforos, trabalhando } \\
\text { em um contexto multidisciplinar e de baixo custo. }\end{array}$ \\
\hline Duração & De quatro a seis aulas práticas (de 8 a 12 horas). \\
\hline $\begin{array}{l}\text { Materiais } \\
\text { utilizados }\end{array}$ & $\begin{array}{l}\text { Tubos Falcon, microtubos, placas de petri, placas de fundo em U com } 96 \text { poços, } \\
\text { palitos estéreis, colunas de cromatografia não polar C18-E, placas de TLC (do } \\
\text { inglês Thin Layer Chromatography, cromatografia em camada fina), meio LB } \\
\text { (Luria-Bertani), hipoclorito de sódio, etanol, solução CAS (cromo azurol S), ácido } \\
\text { trifluoroacético, acetato de etila, acetonitrila, metanol. }\end{array}$ \\
\hline Criação & $01 / 04 / 2018$ \\
\hline Aplicação & 01/05/2018 \\
\hline
\end{tabular}




\section{Introdução}

Os avanços tecnológicos proporcionaram uma geração de conhecimento em escalas nunca imaginadas [1]. Embora benéfico para a sociedade, que fará uso desse conhecimento e o transformará em novas aplicações no futuro, o monitoramento dessa evolução do pensamento científico tornou-se uma tarefa complicada. Essa tarefa exige que os profissionais da educação precisem constantemente interagir com essas novas descobertas por meio de diferentes meios de comunicação para tornar suas aulas mais investigativas e contextualizadas com essa evolução [2]. Ao contrário dessa necessidade, alguns temas e descobertas estabelecidos na segunda metade do século passado, mesmo tendo grande relevância para o conhecimento humano, ainda estão sendo pouco trabalhados no contexto da sala de aula, mesmo no ensino superior. Parte disso se deve à falta de informação nos livros didáticos mais relevantes nas respectivas áreas de conhecimento, uma vez que os sujeitos presentes neles são tratados como assuntos acabados [3], e outra parte é atribuída à falta de recursos, muitas vezes práticos, para tornar esse conhecimento mais acessível [4].

Um bom exemplo está diretamente associado aos processos envolvidos na aquisição e metabolismo do ferro por microrganismos. Embora seja um tópico de ampla aplicação que pode ser trabalhado a partir de diferentes perspectivas e de forma multidisciplinar, as propostas de intervenções práticas voltadas para o ensino de pesquisas sobre o assunto ainda são incipientes [5]. Conhecer e discutir os mecanismos envolvidos nesses processos fisiológicos permitem ao aluno ter uma visão mais holística e integrada das dinâmicas metabólicas que regem a homeostase celular nesses microrganismos. Daí a importância de se trabalhar esse tema sem, no entanto, interferir de forma deletéria no programa curricular dos cursos de Ciências Biológicas e Saúde.

A proposta deste trabalho atende a essa perspectiva e é a primeira vez que o tema é trabalhado em uma proposta multidisciplinar enfatizando o papel dos sideróforos nesse processo molecular.

\section{Desenvolvimento}

A sequência didática foi estabelecida em três momentos pedagógicos: palestra preliminar sobre o assunto; procedimentos experimentais em aulas práticas; avaliação da qualidade dos procedimentos metodológicos e aprendizagem conceitual.

Dois dias antes da aula teórica, os alunos receberam um documento para leitura e para aquisição de conhecimentos teóricos. Esse material retrata, sob a forma de 
transposição didática, a "Importância do ferro no metabolismo e sua disponibilidade no ambiente", o "Mecanismo molecular de aquisição de ferro pelas bactérias" e "A classificação e importância biotecnológica dos sideróforos" (APÊNDICE 1). Os textos contidos no documento foram desenvolvidos pelos autores da proposta e estão disponíveis para uso irrestrito, desde que devidamente referenciados.

Durante a palestra, os temas apresentados no material de apoio foram trabalhados por meio de uma aula dialógica expositiva. Os seguintes tópicos foram contextualizados:

a) A importância do ferro no metabolismo celular.

b) Estados de oxidação do ferro no ambiente.

c) Fatores que interferem nos estados de oxidação do ferro.

d) Mecanismos moleculares de sinalização bacteriana da concentração de ferro no meio (transdução de sinal).

e) Regulação da expressão gênica durante a síntese de sideróforos.

f) Secreção dos sideróforos e quelação do $\mathrm{Fe}^{3+}$ para o meio externo.

g) Mecanismos de transporte de ferro por sideróforos em bactérias gram-positivas e gram-negativas.

h) Armazenamento de ferro no interior da célula.

i) Estresse oxidativo induzido pela reação de Fenton na presença de ferro livre no interior das células.

\section{Procedimento de uso do material ou aplicação da atividade}

As aulas práticas envolveram a coleta das amostras ambientais pelos alunos, o isolamento bacteriano dessas amostras, o crescimento das bactérias em meio de cultura, a extração e purificação de sideróforos utilizando cromatografia de coluna, a identificação e classificação química dos sideróforos por meio de métodos bioquímicos e cromatografia de cama fina. Os procedimentos experimentais detalhados estão disponíveis no material suplementar 1.

\section{Procedimentos de avaliação}

A sequência didática foi avaliada com alunos de mestrado profissional em ensino de ciências. A turma é composta por 14 alunos, todos professores das redes de ensino público e privado do Estado de Minas Gerais. No momento da inscrição, 
participaram 12 alunos, dos quais 9 se tornaram disponíveis para participar do processo de pesquisa de qualidade metodológica.

Duas abordagens foram implementadas: a) avaliação de parâmetros metodológicos investigados qualitativamente por escala de Likert [6] (Tabela 1). Essa avaliação qualitativa foi aplicada imediatamente após a última aula prática, ainda em laboratório; b) avaliação do aprendizado conceitual associado à metodologia. Para essa abordagem, cinco questões técnicas com múltiplas escolhas foram estabelecidas (dados não mostrados) para investigar o grau de assimilação de conceitos fundamentais. Essa etapa foi realizada sete dias após a avaliação qualitativa descrita em "a".

\section{Potencial educacional}

A proposta apresentada possui grande potencial educacional, ao envolver conceitos iniciais em laboratórios de microbiologia como isolamento e crescimento bacteriano até o uso de ensaios bioquímicos e técnicas analíticas cotidianamente utilizadas em laboratórios de pesquisa, permitindo ao professor cobrir diversos conceitos dos cursos de microbiologia e ao aluno a oportunidade de aprender novas técnicas experimentais em um contexto multidisciplinar.

\section{Diferencial com as atividades/materiais preexistentes}

O ferro é um elemento essencial para os seres vivos. Faz parte da estrutura de muitas moléculas importantes e também está envolvido em reações químicas fundamentais. No entanto, muito pouco é discutido com os alunos sobre como os microrganismos, em particular as bactérias, adquirem esse elemento do ambiente, seu potencial biotecnológico e as ferramentas analíticas de purificação e caracterização das moléculas responsáveis pela absorção de ferro [7].

Embora seja uma questão multidisciplinar, continua a ser negligenciada nos cursos de graduação em ciências da vida. Aqui, apresentamos uma sequência didática [8] que permite que os alunos vivenciem a aprendizagem sobre sideróforos por meio de pesquisas, enquanto trabalham em um contexto multidisciplinar e de baixo custo. 


\section{Resultados da avaliação}

\subsection{Desenvolvimento e análise qualitativa da sequência proposta}

Qualitativamente, a sequência didática mostrou-se bastante eficaz. Não só porque torna a proposta de ensino mais integrada entre os alunos ou entre professor e alunos, mas também porque permite uma ampla discussão multidisciplinar a partir de um tema focal no ambiente de sala de aula. Todos os estudantes foram capazes de induzir crescimento de bactérias ambientais em meio de cultura (Figura 1A), isolar colônias bacterianas (Figura 1B), qualificar esses isolados para a produção de sideróforos (Figura 1C), purificar esses sideróforos por meio de colunas cromatográficas (Figura 1D) e qualificar os sideróforos em TLC (do inglês "Thin Layer Chromatography", cromatografia em camada fina) (Figura 2).

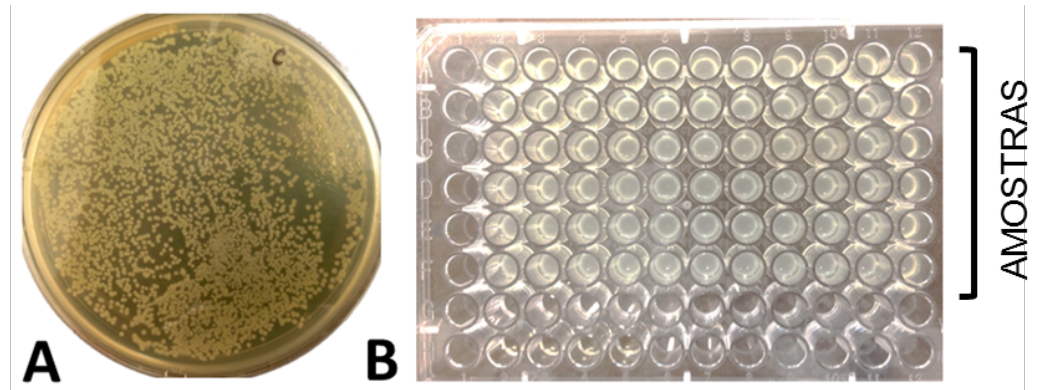

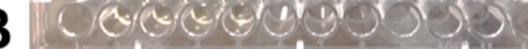

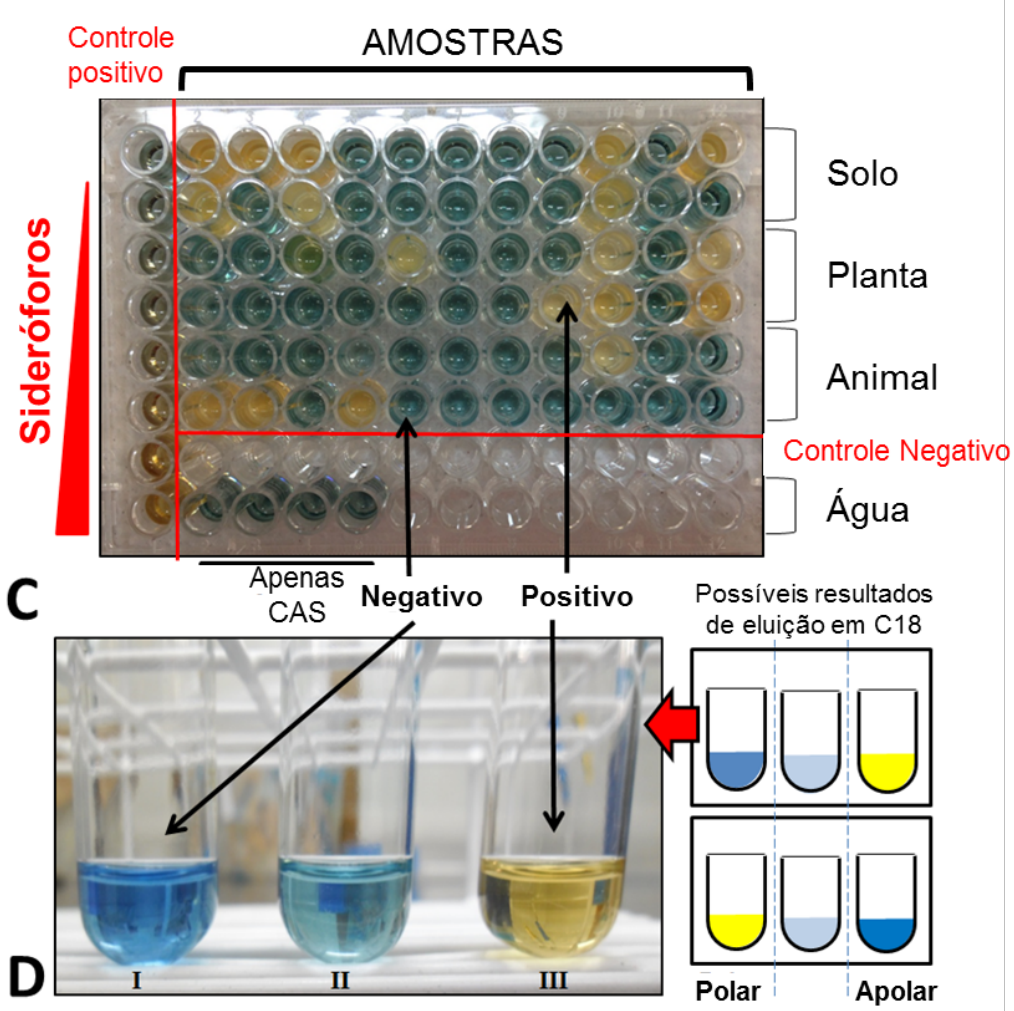

Figura 1. Resultados obtidos em cada uma das etapas propostas para a atividade. (A) Placas de Petri contendo as diferentes colônias obtidas de um substrato. (B) Crescimento dos isolados bacterianos em uma placa de 96 poços para o ensaio CAS (cromo azurol S). (C) Ensaio de produção de sideróforos em uma placa de 96 poços. (D) Ensaio de atividade de sideróforos após a eluição de uma amostra da coluna C18. 


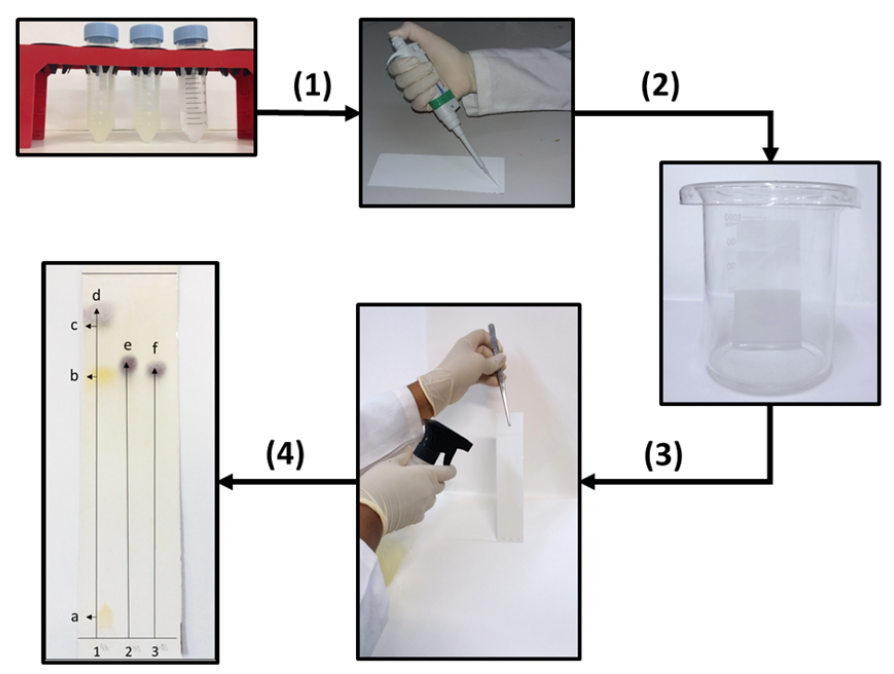

Figura 2. Protocolo de classificação de sideróforos. Isolados crescem em meio M9, depois os sideróforos são extraídos, secos e aplicados à coluna TLC (1). As amostras são eluídas através da TLC à medida que o solvente sobe na placa por ação capilar (2). Após a eluição completa do solvente, uma solução de cloreto férrico é pulverizada na placa (3). A separação do sideróforo. No ponto 1, a desferroxamina (a), o ácido hidroxâmico (b), o ácido cafeico (c) e o ácido 2,3-di-hidroxibezoico (d) são utilizados como padrões. As manchas 2 e 3 são sideróforos (e e f) presentes em um dos isolados.

Embora não seja possível prever o número de isolados que serão obtidos a partir de uma amostra ambiental, é possível isolar bactérias de praticamente qualquer ambiente. Exceções para isso seriam em casos de falha na execução do protocolo ou se uma determinada condição ambiental induziria uma diminuição no número da população, alterando, assim, a dinâmica da ecologia microbiana [9].

É importante discutir com os alunos que colônias com a mesma aparência podem representar microrganismos completamente diferentes, justificando $\mathrm{O}$ isolamento de todas as possíveis colônias e que a distinção entre esses dois isolados pode ser feita por técnicas microbiológicas (coloração de Gram ou motilidade), bioquímicas (metabolismo de moléculas orgânicas específicas ou por ensaios de enzima) ou ainda técnicas moleculares (16S ribossomal, polimorfismo de comprimento de fragmento, número variável de repetições em tandem, etc.).

Quando possível, para os ensaios CAS (cromo azurol S), desenvolver uma diluição progressiva de sideróforos comerciais para ser usada como controle positivo e uma curva de calibração. Embora não seja uma avaliação quantitativa, é possível correlacionar indiretamente a produção de sideróforos com a intensidade da mudança de cor usando essas diluições como referência. Todos os isolados que mudaram a cor do meio para marrom no ensaio CAS são produtores de sideróforos. A placa pode ser lida 
com um espectrofotômetro a $420 \mathrm{~nm}$, permitindo a medição precisa de sideróforos com base em uma curva de titulação [10].

$\mathrm{Na}$ purificação parcial empregando cromatografia em coluna, é importante discutir com os alunos as duas possibilidades de resultados esperados. No caso dos sideróforos polares, a mudança de cor do meio CAS será observada com a primeira fração eluída, enquanto, no caso dos sideróforos apolares, a mudança será observada com a última fração eluída.

Para continuar a atividade, os sideróforos serão classificados de acordo com seu grupo coordenador usando cromatografia. Esse protocolo será utilizado para discutir com os alunos os métodos analíticos para separar e caracterizar compostos. O método TLC permite a classificação dos sideróforos de acordo com sua estrutura química. As manchas foram reveladas com um spray de cloreto férrico. A cor púrpura indica a presença de grupos catecol na molécula, o amarelo representa os ácidos hidroxâmicos, e a cor verde, carboxilatos e grupos catecol misturados nas moléculas, como mostrado nos quatro diferentes isolados de bactérias (Figura 2). Se possível, devem ser usados sideróforos comercialmente disponíveis para demonstrar a diferenciação de cor em cada classe, e a relevância desses grupos químicos para a quelação do ferro devem ser discutidas.

$\mathrm{Na}$ triagem e isolamento de microrganismos, é importante colocar que, embora seja fácil isolar bactérias de qualquer ambiente, o número de isolados obtidos será sempre muito baixo se comparado com a diversidade encontrada no respectivo ambiente. Isso é explicado não apenas pelas características do meio de cultura, que tende a favorecer certos grupos específicos de bactérias, mas também pela dependência mútua dessas bactérias para sobreviverem juntas, caracterizando os chamados consórcios bacterianos [11]. Ao selecionar espécies produtoras de sideróforos isolados, os seguintes aspectos podem ser discutidos: síntese de sideróforos e vias de sinalização, reações redox e afinidade entre ligante e alvo, mecanismos de síntese, e transporte e quelação de íons. Outros assuntos que podem ser tratados são perspectivas de ecologia microbiana, tais como competição e mutualismo, que podem explicar o comportamento de bactérias associadas a raízes de plantas ou processos infecciosos no corpo humano [12]. Durante o passo de purificação parcial e classificação de sideróforos, uma discussão sobre os 
princípios de cromatografia e métodos de purificação de biomoléculas é essencial. Os conceitos básicos de solubilidade, ligações intermoleculares e polaridade podem ser desenvolvidos para contextualizar os mecanismos de separação cromatográfica utilizados nesse protocolo, como partição (Extração em fase sólida C18-SPE) e adsorção (SilicaTLC). Enquanto a técnica de TLC permite a separação e classificação de diferentes grupos de coordenação de $\mathrm{Fe}^{3+}$, a purificação de SPE permite a separação de frações de diferentes polaridades. Isso indica que essas frações podem ser analisadas por cromatografia líquida de alta eficiência e espectrometria de massas para obter uma melhor perspectiva da estrutura dessas biomoléculas.

\subsection{Pesquisa qualitativa e quantitativa sobre metodologia e aprendizagem}

A qualidade da proposta foi investigada pela escala Likert, como mostra a Tabela $1 \mathrm{em}$ Material Suplementar 2. Nessa tabela, dez afirmativas e oito negativas foram associadas a quatro pontos de investigação: (1) Avaliação do tema e objetivos da aula; (2) Avaliação da qualidade da atividade e do ferramental utilizado; (3) Avaliação da aprendizagem e (4) Viabilidade dinâmica/estrutural da proposta metodológica.

Apresenta-se se na figura 3 que para $100 \%$ dos alunos os objetivos propostos na aula foram completamente alcançados (1a) com um fácil entendimento dos assuntos (2a), permitindo a integração total por $67 \%$ dos alunos (1c) e uma ampla discussão dos conceitos-chave entre eles (1d) para $78 \%$ dos alunos, mesmo que o assunto fosse totalmente desconhecido (3b) para $89 \%$ deles. Outra observação importante é que $89 \%$ concordam parcial ou totalmente que as aulas introdutórias iniciais, apoiadas pelo material de apoio (3e), foram fundamentais para o processo de aprendizagem, permitindo a assimilação de informações de forma satisfatória para a mesma porcentagem de alunos (3f). Quanto à viabilidade das propostas experimentais, $89 \%$ afirmaram concordar parcial ou totalmente que, com a estrutura adequada e os materiais disponíveis, é possível executar a sequência didática proposta. Finalmente, para cerca de $78 \%$ dos alunos, a aula possui caráter multidisciplinar (3c). Na tentativa de explicar essa multidisciplinaridade associada à sequência didática proposta, foi estabelecido um diagrama representativo da aplicabilidade temática da atividade (Figura 4). É possível verificar que diferentes áreas do conhecimento (Microbiologia, Ecologia, Química Inorgânica e Analítica, Bioquímica e 
Biologia Molecular) podem utilizar o enfoque temático (sideróforos) em sua abordagem para a promoção de discussões sobre temas específicos.

A

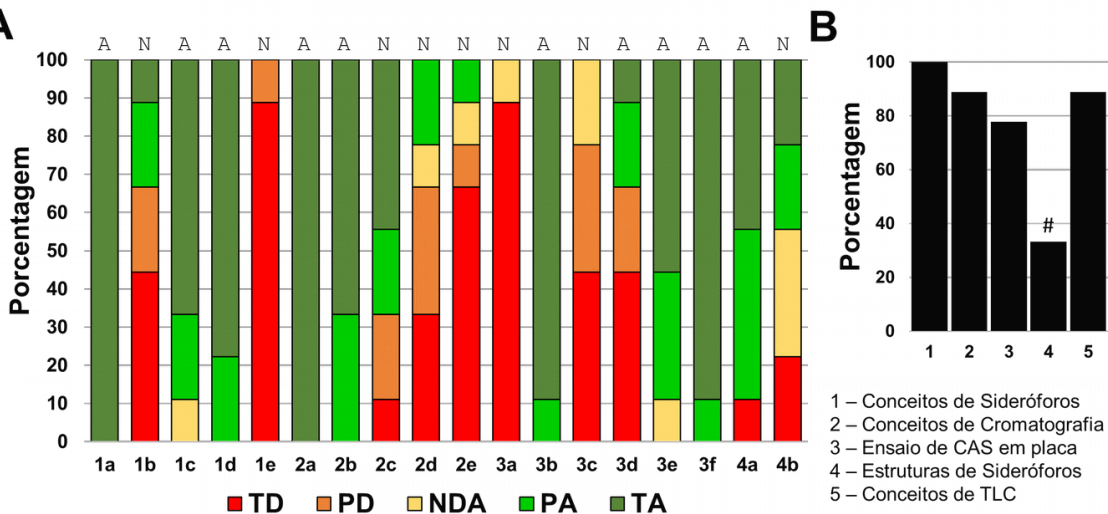

Figura 3. Avaliação da metodologia e aprendizagem. (a) Avaliação qualitativa e quantitativa baseada na escala de Likert. Na abscissa, as afirmações $(A)$ ou negações $(N)$ identificadas na Tabela 1 são resumidas. As cores refletem a porcentagem de respostas dos alunos $(n=9)$ em relação aos itens investigados. TD Discordo Totalmente; PD - Discordo Parcialmente; NDA - Não Discordo ou Concordo; PA - Concordo Parcialmente; TA - Concordo Totalmente. (b) Avaliação qualitativa e quantitativa baseada na assimilação de conceitos. Os números da abscissa denotam os principais conceitos abaixo do gráfico referenciado.

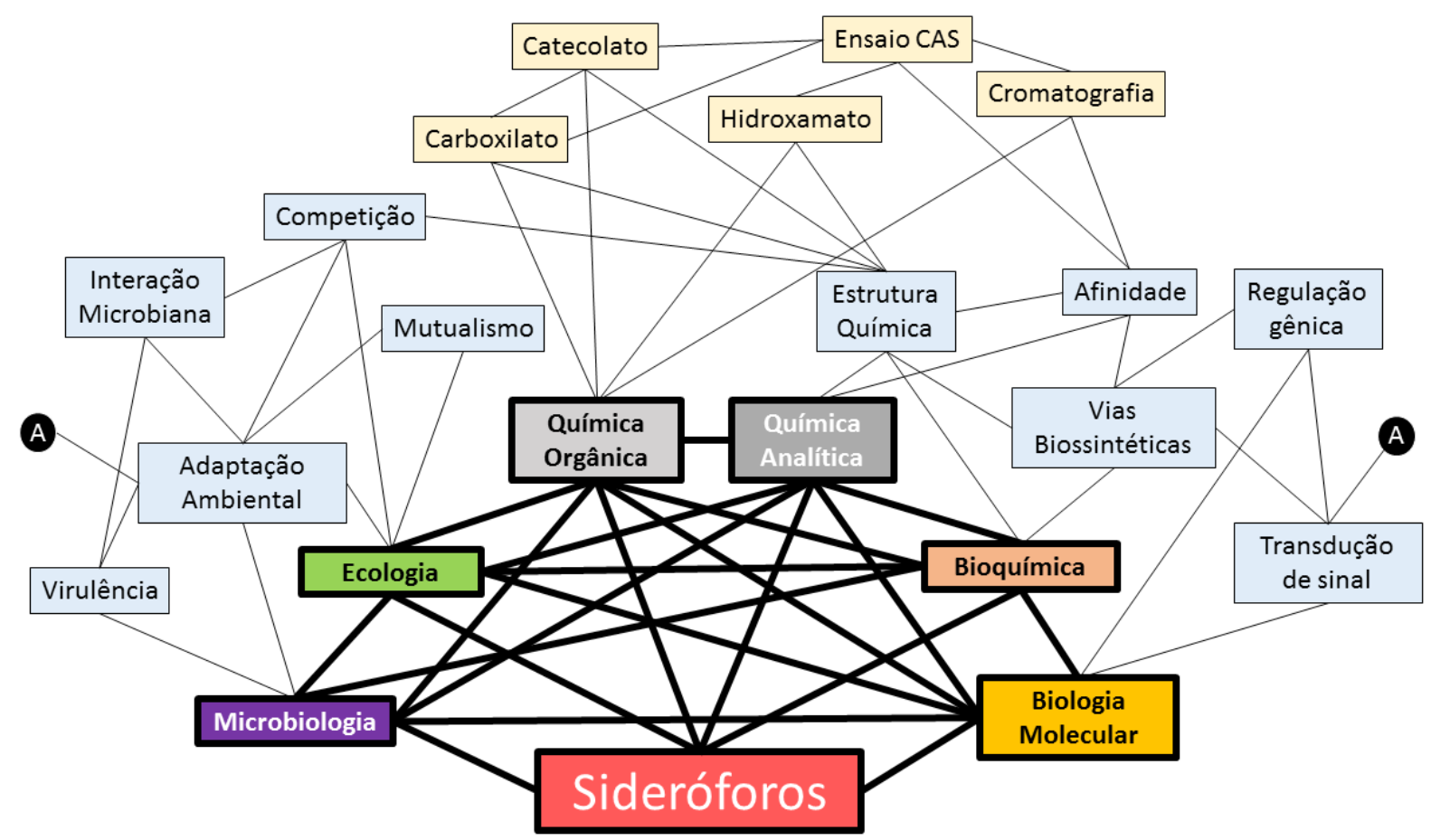

Figura 4. Diagrama representativo da aplicabilidade temática da atividade entre diferentes áreas do conhecimento científico e conceitos, bem como possíveis questões que poderiam ser cobertas com os alunos envolvendo o tema dos sideróforos. As linhas grossas apontam relações multidisciplinares e as linhas finas representam a relação entre os assuntos correlacionados. Azul indica assuntos gerais e amarelo é indicativo de questões mais específicas. A - Representa uma conexão de tema. Essa rede pode ser expandida a critério do professor. 
Quanto ao conceito de aprendizagem, apesar de não ter sido utilizado um grupo de alunos de controle (sem contato com a proposta pedagógica), as respostas baseadas em questões de múltipla escolha foram plenamente satisfatórias. Os estudantes compreenderam totalmente o conceito fundamental e a importância dos sideróforos (100\% de precisão), bem como o princípio fundamental das técnicas cromatográficas e de TLC usadas na proposta (cerca de 90\% de precisão).

No entanto, o conteúdo menos assimilado está relacionado à diversidade estrutural dos sideróforos. Apenas $33 \%$ dos estudantes combinaram a relação de nomes com as estruturas apresentadas na questão. Existem muitas justificativas para esse resultado, no entanto, por serem estudantes de mestrado profissional em ensino de ciências, biólogos de formação, a falta de contato com estruturas químicas mais elaboradas e as dificuldades em classificar as funções orgânicas simples parecem ser o ponto mais forte para essa margem de erro [13].

\subsection{Quantificação dos custos associados à implementação da proposta}

Os custos dos reagentes utilizados nessa sequência didática para cada aluno, considerando o isolamento de um único organismo produtor de sideróforos, foram detalhados na Tabela 2 (Material Suplementar 2). É possível notar que, embora o custo de aquisição de alguns reagentes não convencionais para o laboratório de microbiologia seja inicialmente alto e a utilização de materiais alternativos seja dificultosa, o custo final dos experimentos para cada isolado bacteriano é baixo, em torno de US\$ 6,71. Dados o volume de atividades e a diversidade da proposta, podemos concluir que a sequência didática apresenta baixo custo.

\section{Considerações finais}

A participação ativa dos alunos na sala de aula contribui significativamente para a internalização e compreensão de conceitos e técnicas raramente abordados nas aulas práticas. A familiarização com diferentes métodos envolvendo diferentes áreas do conhecimento científico permite que os estudantes encontrem soluções para problemas específicos e discutam essas soluções, aumentando, assim, a precisão do uso conceitual e a facilidade de apropriação de novos conhecimentos. Neste artigo, propomos uma sequência didática que requer poucos recursos e que envolve uma série de etapas simples que podem ser implementadas a baixo custo em laboratórios de classe prática. $A$ 
ideia central é desenvolver a percepção de que bactérias de diferentes regiões podem produzir substâncias que explicam sua adaptação a diferentes ambientes. Como esse método permite uma investigação em larga escala, um grande número de bactérias pode ser analisado de uma vez, e os resultados podem ser avaliados a olho nu para detectar mudanças simples de cor do meio para indicar se o isolado bacteriano é um produtor de sideróforos. Além disso, é possível avaliar os grupos químicos e a polaridade dessas moléculas com rapidez e precisão utilizando colunas cromatográficas e placas de TLC. Por fim, essa abordagem permite que os alunos vivenciem várias etapas da pesquisa científica e integrem essas etapas à dinâmica da aula.

\section{Referências}

[1] Rinaldi A. Naturally better. Science and technology are looking to nature's successful designs for inspiration. EMBO Rep. 2007 Nov;8(11):995-999.

[2] Diniz RES, Campos LML, Kühl LW. Os novos conhecimentos no campo da biologia e a sala de aula: proposta de formação continuada de professores. In: Pinho SZ, Saglietti JRC, organizadores. Unesp escola: Núcleos de Ensino. Universidade Estadual Paulista, Pró-Reitoria de Graduação: Editora da UNESP; 2006. p. 264-278.

[3] Neto M, Fracalanza JH. O livro didático de ciências: problemas e soluções. Ciênc educ. (Bauru). 2003;9(2):147-157. ISSN 1516-7313.

[4] Moresco TR, Carvalho MS, Klein V, Lima AS, Barbosa NV, Rocha JB. Ensino de microbiologia experimental para Educação Básica no contexto da formação continuada. Rev Electr Enseñ Cienc. 2007;16(3):435-57.

[5] Louden BC, Haarmann D, Lynne AM. Use of blue agar CAS assay for siderophore detection. J Microbiol Biol Educ. 2011;12(1):51-3.

[6] Rønn R, McCaig AE, Griffiths BS, Prosser JI. Impact of protozoan grazing on bacterial community structure in soil microcosms. Appl Environ Microbiol. 2002;68(12):6094-6105.

[7] Miethke M, Marahiel MA. Siderophore-based iron acquisition and pathogen control. Microb Mol Biol Rev. 2007;71(3):413-451.

[8] Denardi DAC. Didactic sequence: a dialetic mechanism for language teaching and learning. Rev. bras linguist apl. 2017;17(1): 163-184.

(9] Ankur J, Saket K, Satish C, Pal DK. Likert scale: explored and explained. Brit J Appl Sci Tech. 2015;7(4):396-403.

[10] Nowak-Thompson B, Gould SJ. A simple assay for fluorescent siderophores produced by Pseudomonas species and an efficient isolation of pseudobactin. Biometals. 1994;7(1):20-4.

[11] Stewart, EJ. Growing unculturable bacteria. J Bac. 2012;194(16):4151-4160.

[12] Eric P, Skaar EP. The battle for iron between bacterial pathogens and their vertebrate hosts. PLoS Pathog. 2010;6(8):e1000949.

[13] Wood EJ. Biochemistry is a Difficult Subject for Both Student and Teacher. Bioch educ. 1990;18(4):170171. 


\section{Agradecimentos}

Agradecemos a todos os membros do Laboratório de Genômica e Interação Bactéria-Ambiente (GIBA, Universidade Federal de Ouro Preto, UFOP), do Laboratório de Reparo de DNA (DNA Lab, Universidade Federal de Ouro Preto, UFOP) e à Talita Raquel Luz Romero pelo apoio.

\section{Financiamento}

Este trabalho foi apoiado pelo Conselho Nacional de Desenvolvimento Científico e Tecnológico (CNPq) [481226/2013-3]; a Fundação de Amparo à Pesquisa do Estado de Minas Gerais (FAPEMIG) [APQ-02387-14; APQ-02357-17]. Leandro Marcio Moreira é bolsista de produtividade do CNPq. 